\title{
Acute pericarditis
}

\author{
Márcio Tonini ${ }^{1 *}$, Dirceu Thiago Pessoa de Melo², Fábio Fernandes ${ }^{3}$ \\ ${ }^{1}$ M.D., Researcher, Heart Institute (InCor), Faculty of Medicine, University of São Paulo (FMUSP), Cardiomyopathy Group, São Paulo, SP, Brazil \\ ${ }^{2}$ M.D., Graduate Student, InCor-FMUSP, Cardiomyopathy Group, São Paulo, SP, Brazil \\ ${ }^{3}$ Assistant Physician, InCor-FMUSP, Cardiomyopathy Group; Post-doctoral Cardiology Professor at FMUSP, São Paulo, SP, Brazil
}

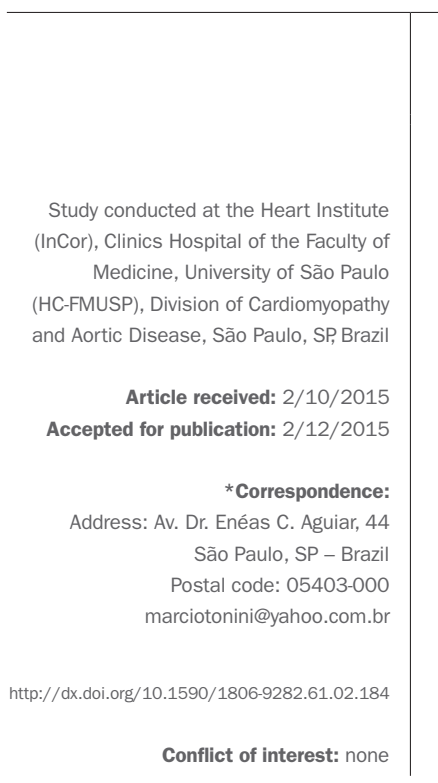

\section{SUMMARY}

Acute pericarditis is a common disease caused by inflammation of the pericardium, usually benign and self-limited and can occur as an isolated or as a manifestation of a systemic disease entity. Represents $5 \%$ of all causes of chest pain in the emergency room. The main etiology are viral infections, although it can also be secondary to systemic diseases and infections. The main complication of acute pericarditis is pericardial effusion, triggering a cardiac tamponade. The first line of treatment is the use of anti-inflammatory and or acetylsalicylic acid. Most patients have a good initial response to an NSAID associated to colchicine and became asymptomatic within a few days.

This review article seeks to contemplate the main clinical findings and armed investigation to optimize the diagnosis of this important disease, as well as addressing their therapeutic management.

Keywords: acute pericarditis, pericardial effusion, chest pain, colchicine.

\section{Clinical definition}

The pericardium is a fibroelastic sac composed of two layers (visceral and parietal), separated by a virtual space called the pericardial cavity, which is filled with 15 to 50 $\mathrm{mL}$ of plasma ultrafiltrate in healthy subjects.

Acute pericarditis is a common disease caused by inflammation of the pericardium, usually benign and selflimited, and may occur as an isolated entity or as a manifestation of a systemic disease.

The real incidence and prevalence of pericarditis is difficult to quantify. Necropsy studies suggest a prevalence of approximately $1 \%$. It affects mainly young males (aged between twenty and fifty years) without previous pathologies and represents $5 \%$ of all causes of chest pain in the emergency room. In developed countries, about $80-90 \%$ of cases are idiopathic, assuming that its main etiology is viral infection, although it can also be secondary to systemic diseases and infections. ${ }^{1,2}$

The main specific causes are cancer and connective tissue diseases (especially systemic lupus erythematosus). It is worth mentioning two rare, genetically determined autoimmune diseases, namely tumor necrosis factor (TNF) receptor 1A-associated periodic syndrome (TRAPS) and familial Mediterranean fever, which may be causes of recurrent pericarditis. ${ }^{3,4}$
With the advent of early coronary reperfusion therapy there was a sharp drop in the incidence of transmural myocardial infarction and, consequently, post-myocardial infarction pericarditis, both early-onset (i.e. 2 to 4 days after myocardial infarction) and late-onset (also called Dressler's syndrome), which became uncommon. ${ }^{3}$

The incidence of acute pericarditis is difficult to quantify, since mild cases can be resolved spontaneously without being diagnosed. ${ }^{5}$

In Brazil, there are no official epidemiological data on pericardial impairment. ${ }^{6}$

Approximately one third of cases of idiopathic pericarditis are associated with myocarditis, which is manifested by elevation of myocardial injury biomarkers, such as troponin I. ${ }^{7}$

Left ventricular dysfunction and heart failure are rare, and clinical presentation with arrhythmias is uncommon in patients with myocarditis. The long-term prognosis for patients who have idiopathic pericarditis with associated myocarditis is excellent. ${ }^{7,8}$

The evolution to constrictive pericarditis is rare in idiopathic or viral acute pericarditis $(<0.5 \%)$, although not negligible. For other specific etiologies it is much more common, such as $2.8 \%$ in pericarditis related to connective tissue diseases, $4.0 \%$ in tumors, $20 \%$ in tuberculosis 
and $33 \%$ in purulent pericarditis. Constriction may be transient or reversible in $15 \%$ of patients with acute pericarditis. $^{9}$

Patients with idiopathic forms and a recurrent course have not shown constrictive progression, and the data are consistent with the previous observation that idiopathic recurrent pericarditis does not lead to constrictive pericarditis. ${ }^{10}$

Data from a recent randomized clinical trial with colchicine for acute pericarditis (ICAP trial) indicate that pericardial effusions are present in about two thirds of patients with acute pericarditis. The vast majority of these effusions are small and without major repercussions. Larger effusions (> $20 \mathrm{~mm}$ in width, as determined by echocardiography) are present in about $3 \%$ of cases. ${ }^{10}$

The main complication of acute pericarditis is pericardial effusion triggering cardiac tamponade. ${ }^{3}$

In $70-90 \%$ of patients, idiopathic acute pericarditis is self-limiting, responding well to treatment, with full resolution. ${ }^{1-3}$

A small number of patients, less than $5 \%$, do not satisfactorily respond to initial treatment, and 10 to $30 \%$ of patients will relapse after an initial response. ${ }^{3}$

Less than $5 \%$ of the total population with acute pericarditis has multiple recurrences. ${ }^{9}$

\section{Clinical picture}

The clinical symptoms in most patients consist of viral prodrome with fever, myalgia and symptoms of the upper respiratory tract or gastrointestinal tract. Subsequently, there is chest pain with pleuritic characteristics, sudden onset, high intensity, which worsens with deep inspiration and radiates to the neck and upper limbs. Irradiation to the trapezius muscle is very suggestive of the diagnosis, and is due to the close relationship between the phrenic nerve - which innervates the trapezius muscle - and the pericardium. Often the pain has postural character, worsening in supine position and improving when sitting. ${ }^{1}$

Other causes of chest pain that can be confused with acute pericarditis are pleuritis with or without associated pneumonia (which coexists with pericarditis in up to one third of the cases), costochondritis, gastroesophageal reflux, pulmonary embolism or infarction, and herpes zoster before the appearance of blisters. ${ }^{15}$

Cardiac tamponade is suspected with increased jugular venous pressure, muffled heart sounds and hypotension (Beck's Triad), or a paradoxical pulse., ${ }^{1,3}$

\section{Physical examination}

The physical examination may reveal a febrile patient with toxemia, tachycardia and lung assessment suggestive of pleural effusion. Pericardial friction is present in $85 \%$ of cases and is characterized by rough, irregular sounds heard best at the left sternal border. This may have an intermittent character, so it is important to conduct a series of physical examinations. ${ }^{8}$

\section{SUPPLEMENTARY EXAMINATIONS}

- Electrocardiogram (class I recommendation, level of evidence C): 6 occasionally we find electrocardiographic changes such as concave upwards ST elevation (Figure 1), and one should differentiate pericarditis between acute myocardial infarction and early repolarization. Another typical finding is PR segment depression. Typically there is more frequent involvement of DI, DII, aVF and V3-V6 derivations. In the natural evolution, four stages are described:

- Stage I ( $80 \%$ of cases): concave up ST with anterior and inferior elevation. PR segment deviation with opposite polarity to the $\mathrm{P}$ wave.

- Early-onset stage II: reversal of changes in the ST segment, PR segment diverted.

- Late-onset stage II: progressive flattening and T wave inversion.

- Stage III: generalized T wave inversion.

- Stage IV: electrocardiogram returns to baseline rate.

- Laboratory testing: leukocytosis, elevated CRP and ESR are common. Changes in myocardial necrosis markers (CK-MB and troponin) may occur for epicardial impairment and should suggest a diagnosis of myopericarditis. Assessments of viral serology and culture for virus have low diagnostic sensitivity, and

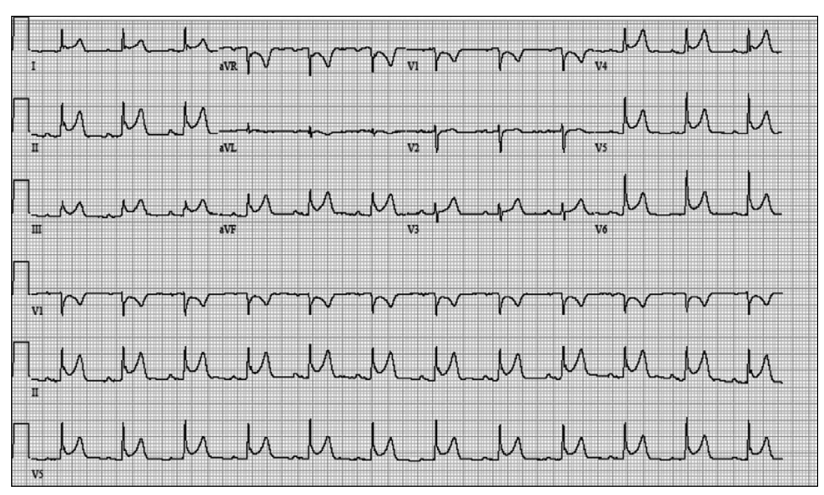

FIGURE 1 ECG showing diffuse ST segment elevation.

(Adapted from the Journal of the American Society of Echocardiography 2013, 26, 965-1012) 
evidence of rheumatic activity such as ANF and RF should be guided by clinical suspicion of autoimmune disease.

- Chest radiography (class I recommendation, level of evidence C): ${ }^{6}$ normal in most patients; however, enlargement of the heart may occur in the presence of pericardial effusion $>200 \mathrm{~mL}$ or in cases of myopericarditis with acute heart failure and dilatation of the heart chambers. A low-volume but quickly accumulated effusion can cause cardiac tamponade without extending the silhouette, which reinforces the importance of echocardiography in patients with acute pericarditis, even if the cardiac silhouette is normal to the X-ray. ${ }^{1}$

- Echocardiogram (class I recommendation, level of evidence $B):{ }^{6}$ this is important to detect the presence of pericardial effusion, signs of tamponade (Figures 2 and 3 ) or altered segmental contractility. It is indicated in all cases involving diagnostic uncertainty or signs of hemodynamic impairment.

- Computed tomography and cardiac magnetic resonance (class IIa recommendation, level of evidence B): ${ }^{6}$ these have good sensitivity for detection of pericardial effusion, assessing the thickness of the pericardium and myocardial impairment. The most sensitive method to detect acute pericarditis is delayed enhancement using MRI. In this imaging exam, the pericardium usually appears black due to its low water content; however, in patients with pericarditis, gadolinium uptake in the inflamed pericardium is delayed, appearing bright in the image (Figures 4 and 5).

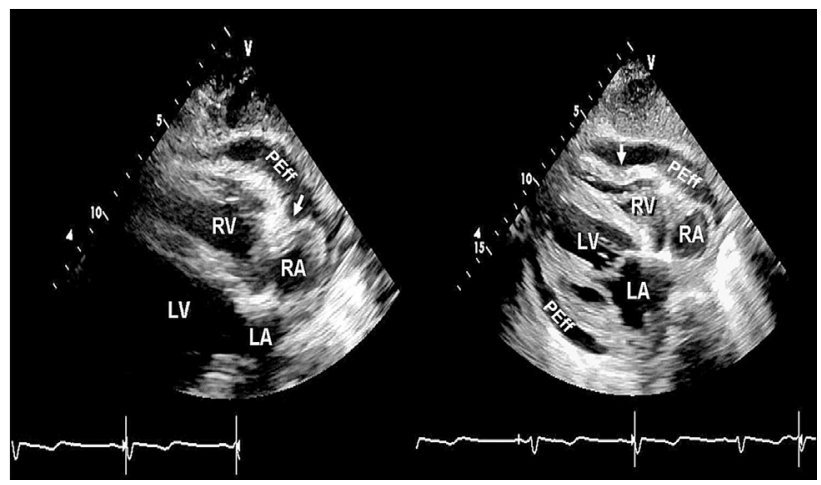

FIGURE 2 Subcostal two-dimensional echocardiography of the heart in a patient with cardiac tamponade showing collapse of the right atrium and ventricle (small arrows).

LA: left atrium; LV: left ventricle; RA: right atrium; RV: right ventricle. (Adapted from the Journal of the American Society of Echocardiography 2013, 26, 965-1012)

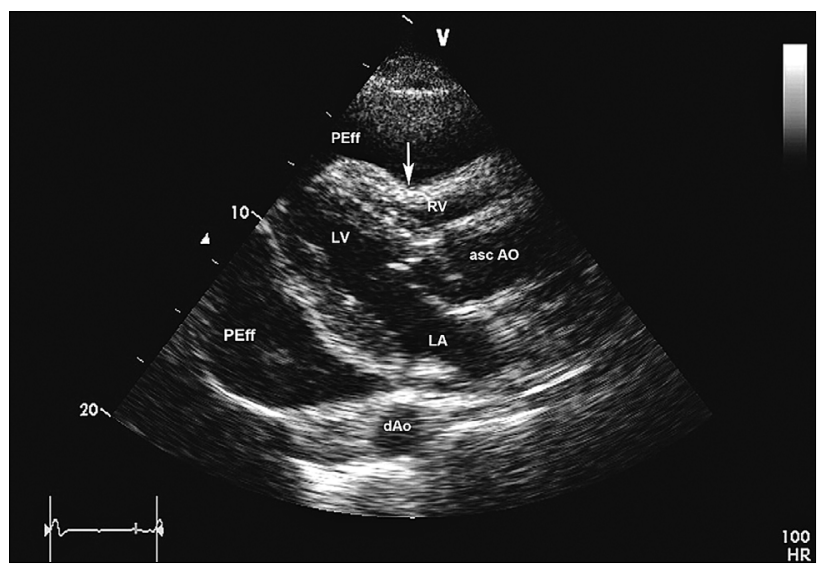

FIGURE 3 2D echocardiography, parasternal long axis view, showing cardiac tamponade. Note the large, circumferential effusion with diastolic collapse of the right ventricle (arrow).

(Adapted from the Journal of the American Society of Echocardiography 2013, 26, 965-1012)

\section{Diagnosis}

The diagnostic criteria for acute pericarditis include: respiratory-dependent chest pain, generalized elevation of the ST segment or PR depressions not previously reported and appearance or presence of pericardial effusion (Figure 6). A clinical diagnosis of acute pericarditis can be made when at least two of these criteria are present. The presence of elevated inflammatory markets (C-reactive protein and/or erythrocyte sedimentation rate) can be used to confirm the diagnosis (Table 1). ${ }^{11,12}$

Hospitalization is recommended when any of the following is present: $38^{\circ} \mathrm{C}$ fever, sub-acute onset, use of anticoagulation, immunosuppression, hypotension, distention and significant effusion. ${ }^{13}$

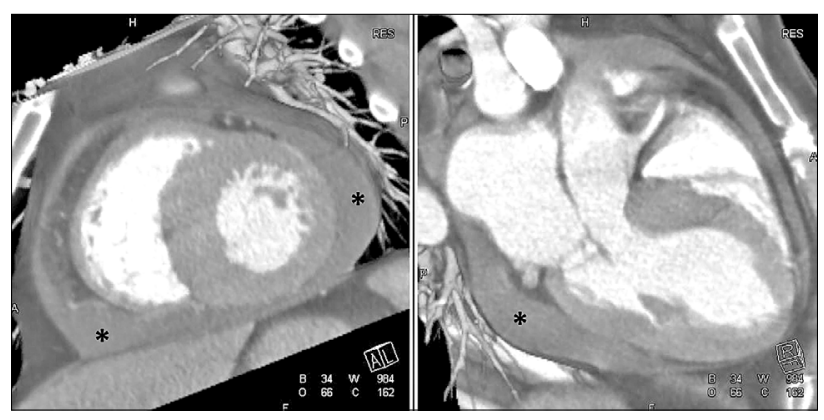

FIGURE 4 Dynamic computed tomography images in the short axis (left) and the outflow tract of the left ventricle show pericardial effusion with focal collections (asterisks).

(Adapted from the Journal of the American Society of Echocardiography 2013, 26, 965-1012) 


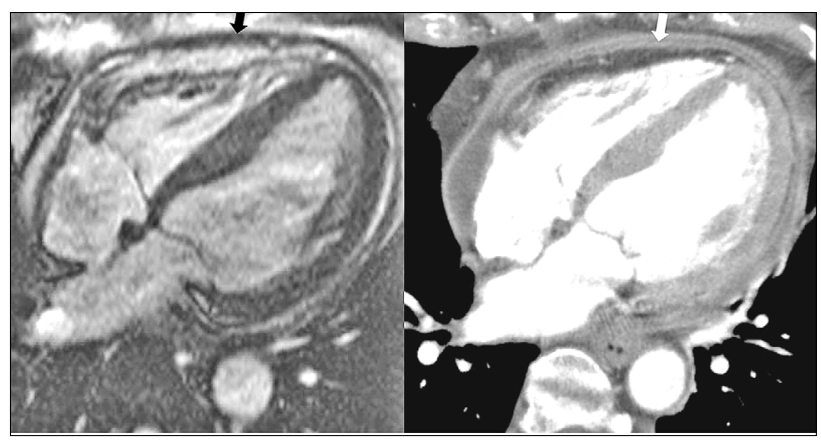

FIGURE 5 Overall pericardial thickening, affecting both layers (parietal and visceral), associated with pericardial effusion. To the left, image obtained by magnetic resonance imaging; to the right, computed tomography with contrast.

Adapted from the Journal of the American Society of Echocardiography 2013, 26, 965-1012.
TABLE 1 Diagnostic criteria for acute pericarditis (the presence of two criteria is considered a diagnosis).

Typical chest pain

Pericardial friction

ECG changes compatible with pericarditis

New or worsening of prior pericardial effusion

Elevation of inflammatory markers (us-CRP or ESR)

Computed tomography or magnetic resonance imaging can confirm the diagnosis

* Adapted from Imazio et al. Controversial issues in the management of pericardial diseases. Circulation 2010;121: 916-28.

\section{Treatment}

The first line of treatment (Table 2) is the use of anti-inflammatory drugs and/or acetylsalicylic acid. ${ }^{5}$ In a study

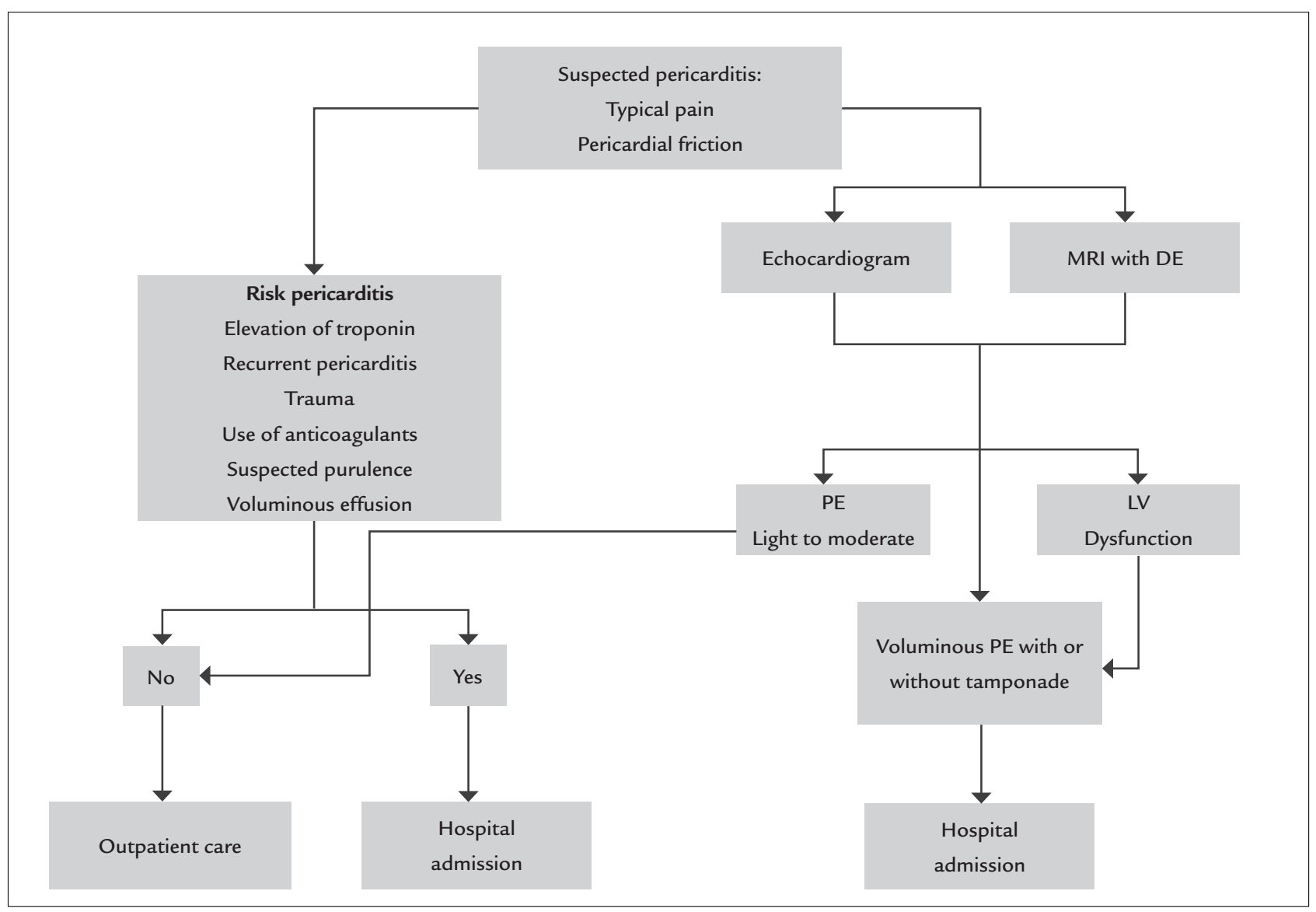

FIGURE 6 Clinical diagnosis

Adapted from Montera MW, et al. Sociedade Brasileira de Cardiologia. I Diretriz Brasileira de Miocardites e Pericardites. Arq Bras Cardiol 2013; 100(4 supl. 1): 1-36 PE: pericardial effusion; MRI: Magnetic resonance imaging; DE: delayed enhancement; LV: left ventricle. 
of 254 patients, the use of ASA in patients with uncomplicated pericarditis relieved the symptoms in $87 \%$ of cases. ${ }^{8}$ Non-steroidal anti-inflammatory drugs (NSAIDs) should be used in the initial period of 7 to 14 days, and treatment duration depends on clinical improvement and normalization of levels of inflammatory markers, such as CRP and ESR. Ibuprofen is also widely used because it does not interfere with the coronary flow.

The most commonly used agents are ibuprofen (600 to $800 \mathrm{mg}$, every 6 to 8 hours), indomethacin ( 25 to 50 mg, every 8 hours), and aspirin ( 2 to $4 \mathrm{~g}$ per day, divided into doses). Ibuprofen has been the drug of choice in North America, whereas aspirin tends to be preferred in Europe. Patients receiving these drugs should also receive a proton-pump inhibitor for gastric protection. ${ }^{23}$

Aspirin is the preferred NSAID in patients with symptomatic pericarditis occurring during the early post-myocardial infarction period, and in combination with colchicine for the majority of other patients in need of concomitant antiplatelet therapy., ${ }^{2,14}$

The anti-inflammatory effects of colchicine are related to the disruption of microtubule function, which results in the inhibition of neutrophils and adhesion molecules that interfere with the initiation and amplification of inflammation. It also acts in the migration of granulocytes and other cells, reducing the activity of phagocytes. ${ }^{15,16}$

Colchicine is rapidly absorbed in the jejunum and ileum and its lipophilic nature allows it to be absorbed by multiple cells, binding itself to its primary target which is tubulin. Colchicine is predominantly eliminated by biliary excretion and to a lesser extent (5 to $20 \%$ ) by the enteric and hepatic cytochrome P 450 system. Renal elimination accounts for 10 to $20 \%{ }^{16}$

Colchicine has been used in recurrent pericarditis (CORP). This study evaluated and randomized 120 patients with the first recurrence using colchicine or placebo in addition to aspirin or other NSAIDs. The recurrence rate was $24 \%$ in those randomized to colchicine and $55 \%$ in the placebo group. Furthermore, the number of episodes was reduced and the time until the following recurrence was prolonged. The duration of colchicine treatment was 6 months. ${ }^{17}$

Recently, evidence of the ICAP randomized trial ${ }^{11}$ involving patients with a first episode of pericarditis, strongly supported this recommendation.

In the ICAP trial, ${ }^{11}$ patients were treated with an antiinflammatory drug (most commonly aspirin) and were randomly assigned to receive either colchicine $(0.5 \mathrm{mg}$ twice daily, for patients weighing > $70 \mathrm{~kg}$, or $0.5 \mathrm{mg}$ per day, to patients with $\leq 70 \mathrm{~kg}$ body weight for 3 months) or a placebo.
Treatment with colchicine, compared to the placebo, resulted in a significantly lower rate of persistent or recurrent pericarditis (17 versus 38\%) and a lower rate of persistent symptoms after 72 hours (19 versus $40 \%$ ).

For colchicine, a course of three months is reasonable based on results of the ICAP trial. The usual duration of NSAID treatment, according to the opinion of specialists, is 1-2 weeks, with the actual duration driven by the clinical response, with gradual rather than abrupt cessation recommended, although there is no evidence to support this. In the ICAP trial, ${ }^{11}$ the treatment strategy with NSAIDs was not specified in advance but patients received treatment with NSAIDs for 7 to 10 days, followed by weaning. ${ }^{1,2,6,18}$

Most patients have a good initial response to NSAID drugs associated with colchicine, and become asymptomatic within a few days. Patients with no or with only limited effusion, and adherent to NSAID-colchicine treatment can be treated as outpatients. ${ }^{19}$

A study of the use of a screening protocol for 300 patients with acute pericarditis showed that low risk patients (i.e. those with sub-acute onset who had no fever, immunosuppression, trauma, myopericarditis, a large pericardial effusion or pericardial tamponade and who were not receiving anticoagulants), which account for $85 \%$ of patients in general, could safely be treated on an outpatient basis; only $13 \%$ of these patients required subsequent admission (for aspirin failure), and there were no major complications. ${ }^{3,13}$

It has been proposed that the normalization of C-reactive protein levels in high sensitivity tests (initially increased) may be used to guide the duration of NSAID therapy, although there are no data to validate this strategy. ${ }^{2}$

Poor initial response to NSAID and colchicine - defined as persistent chest pain requiring analgesics, fever, worsening effusion, despite at least 1 week of treatment - is unusual, and becomes a difficult problem to manage. This also leads to an increased possibility of identifying a specific cause. ${ }^{1}$

For patients with poor or inadequate response, the association of glucocorticoids is recommended. If the adverse effect profile is acceptable, the NSAID treatment should be maintained.

Corticosteroids should be avoided in acute pericarditis, except in rheumatologic cases, considering the increase of the recurrence rate of pericarditis, as well as the possibility of reducing the effect of colchicine in preventing recurrence. The recommended dose is 0.25 to $0.5 \mathrm{mg} / \mathrm{kg}$, which indicates gradual removal. Weaning should be done every 5-10 mg, every 2 weeks, for patients with daily use of 
25 to $50 \mathrm{mg}$ of prednisone; for those using a dose of 15 to $25 \mathrm{mg}$ of prednisone per day, weaning should be done every $2.5 \mathrm{mg}$, every 2 to 4 weeks; and for patients taking daily doses lower than $15 \mathrm{mg}$ of prednisone, it is recommended weaning from 1-2.5 mg, every 2 to 6 weeks. ${ }^{1,6,10}$

\section{RECURRENT PERICARDITIS}

The risk of recurrence is higher for women and for patients who do not respond to initial treatment with NSAIDs. ${ }^{20}$

The treatment of a recurrence (Table 2) should start with the rapid resumption of NSAID therapy at the same dosage of the initial episode., ${ }^{2,3}$ If treatment with colchicine was not administered initially, it should be administered for recurrence because there is evidence from randomized clinical trials that this reduces the risk of recurrence after one or multiple recurrences. ${ }^{6,14}$

In many cases, patients have a good response to the reintroduction of NSAID treatment and should be encouraged to resume treatment with an NSAID in the future, at the first symptom of recurrence. ${ }^{3}$

Recurrences can be conducted in this way, since NSAIDs continue to be effective, with an acceptable side effect profile, and while symptoms are not disabling.

In unusual cases involving patients who have frequent recurrences or who have a poor response to reinstitution of therapy with NSAIDs, glucocorticoids are also used..$^{1,6}$

Treatment plan should be the same as for patients with a poor response to initial treatment. For the reasons described above, treatment with glucocorticoids should be avoided, if possible. The experience with other immunomodulatory agents in refractory recurrent pericarditis is very limited, but studies involving a small number of patients demonstrate improvements after treatment with immunoglobulin, anti-tumor necrosis factor- $\alpha$, antibody, methotrexate, azathioprine, anakinra, or interleukin- $1 \beta$ antagonists. ${ }^{3,20,21}$

Although recurrent pericarditis can be very disabling, patients without an identified underlying cause seldom progress to serious subsequent complications (e.g. constrictive pericarditis). ${ }^{19}$

Pericardiectomy has occasionally been indicated to treat refractory recurrent pericarditis. Case series studies suggest a clinical benefit. ${ }^{22}$

Pericardiectomy is not consistently effective, perhaps because visceral pericardium remains after the procedure, along with remnants of parietal pericardium. ${ }^{3}$

Patients with cardiac tamponade should undergo urgent therapeutic pericardiocentesis.

Pericardiocentesis should also be considered for patients with large effusions without tamponade, in the rare cases where patients have myocarditis and heart failure, who should be hospitalized for observation and appropriate treatment introduction. ${ }^{1,8}$

Little is known about the pathophysiology of recurrent pericarditis. Some patients have no evidence of pericardial inflammation during recurrences, and it is unclear whether patients with recurrences have an active viral infection or an immunological basis for the syndrome.

One study indicated that HLA allele patterns are associated with recurrent pericarditis, however, new studies are needed in order to confirm this possibility.

More data is needed to inform the role of new forms of immunomodulating therapy in the treatment of patients with refractory recurrent pericarditis.

TABLE 2 Treatment of acute and recurrent pericarditis. ${ }^{6}$

\begin{tabular}{|c|c|c|}
\hline Medication & Dosage & Treatment duration \\
\hline ASA & $\begin{array}{l}500-750 \mathrm{mg}, 3 \text { to } \\
4 \text { times/day }\end{array}$ & $\begin{array}{l}\text { 7-10 days, followed } \\
\text { by a gradual } \\
\text { reduction of } 500 \mathrm{mg} / \\
\text { week, over } 3 \text { weeks }\end{array}$ \\
\hline Ibuprofen & $400-800 \mathrm{mg}, 3$ to 4 times/day & 14 days \\
\hline $\begin{array}{l}\text { Indomethacin } \\
\text { * Avoid after } \\
\text { AMI }\end{array}$ & $50 \mathrm{mg}, 3$ times/day & 1-2 weeks \\
\hline Colchicine & $\begin{array}{l}0.5 \mathrm{mg}, 2 \text { times/day or } \\
0.5 \mathrm{mg}, 1 \text { times/day } \\
\text { (patients weighting < } 70 \\
\mathrm{Kg} \text { ) }\end{array}$ & $\begin{array}{l}3 \text { months in the first } \\
\text { event } \\
6 \text { months upon } \\
\text { recurrence }\end{array}$ \\
\hline Prednisone & 0.25 to $0.5 \mathrm{mg} / \mathrm{kg} / \mathrm{day}$ & $\begin{array}{l}2 \text { weeks } \\
\text { 2-4 weeks of } \\
\text { recurrence }\end{array}$ \\
\hline
\end{tabular}

\section{Resumo}

Pericardite aguda.

A pericardite aguda é uma doença comum causada pela inflamação do pericárdio, geralmente benigna e autolimitada, podendo ocorrer como entidade isolada ou como manifestação de uma patologia sistêmica. Representa 5\% de todas as causas de dor torácica na sala de emergência. A principal etiologia são as infecções virais, embora também possa ser secundária a afecções sistêmicas. A principal complicação da pericardite aguda é o derrame pericárdico, desencadeando um tamponamento. A primeira linha de tratamento é uso de anti-inflamatórios ou ácido acetilsalicílico. A maioria dos pacientes tem boa resposta inicial a um anti-inflamatório não esteroide (AINE) as- 
sociado à colchicina e torna-se assintomática em poucos dias. Este artigo busca contemplar os principais achados clínicos e de propedêutica armada para otimizar o diagnóstico dessa patologia, bem como abordar o seu manejo terapêutico.

Palavras-chave: pericardite aguda, derrame pericárdico, dor torácica, colchicina.

\section{References}

1. Maisch B, Seferović PM, Ristić AD, et al. Guidelines on the diagnosis and management of pericardial diseases executive summary: the Task Force on the Diagnosis and Management of Pericardial Diseases of the European Society of Cardiology. Eur Heart J 2004;25:587-610.

2. Seferović PM, Ristić AD, Maksimović R, et al. Pericardial syndromes: an update after the ESC guidelines 2004. Heart Fail Rev 2013;18:255-66.

3. LeWinter MM. Acute Pericarditis. N Engl Med 2014; 371:2410-6.

4. Rigante D, Cantarini L, Imazio M, et al. Autoinflammatory diseases and cardiovascular manifestations. Ann Med 2011;43:341-6.

5. Dudzinski DM, Mak GS, Hung JW. Pericardial diseases. Curr Probl Cardiol 2012;37:75-118.

6. Montera MW, Mesquita ET, Colafranceschi AS, Oliveira Junior AM, Rabischoffsky A, Ianni BM, et al. Sociedade Brasileira de Cardiologia. I Diretriz Brasileira de Miocardites e Pericardites. Arq Bras Cardiol 2013; 100(4 supl. 1): 1-36.

7. Buiatti A, Merlo M, Pinamonti B, DeBiasio M, Bussani R, Sinagra G. Clinical presentation and long-term follow-up of perimyocarditis. J Cardiovasc Med (Hagerstown) 2013;14:235-41.

8. Imazio M, Brucato A, Barbieri A, et al. Good prognosis for pericarditis with and without myocardial involvement: results from a multicenter, prospective cohort study. Circulation 2013;128:42-9.

9. Imazio M, Brucato A, Maestroni S, Cumetti D, Belli R, Trinchero R, Adler $\mathrm{Y}$. Risk of constrictive pericarditis after acute pericarditis Circulation. 2011;124(11):1270-5
10. Imazio M, Brucato A, Adler Y, Brambilla G, Artom G, Cecchi E, et al. Prognosis of idiopathic recurrent pericarditis as determined from previously published reports. Am J Cardiol. 2007;100:1026-1028.

11. Imazio M, Brucato A, Cemin R, et al. A randomized trial of colchicine for acute pericarditis. N Engl J Med 2013;369:1522-8.

12. Imazio M, Cecchi E, Demichelis B, Ierna S, Demarie D, Ghisio A, et al. Indicators of poor prognosis of acute pericarditis. Circulation. 2007;115:27392744 .

13. Imazio M, Brucato A, Maestroni S, Cumetti D, Dominelli A, Natale G, Trinchero R. Prevalence of C-reactive protein elevation and time course of normalization in acute pericarditis: implications for the diagnosis, therapy, and prognosis of pericarditis. Circulation. 2011;123:1092-1097.

14. Lilly LS. Treatment of acute and recurrent idiopathic pericarditis. Circulation. 2013;127(16):1723-6.

15. Niel E, Scherrmann JM. Colchicine today. Joint Bone Spine. 2006;73(6):672-8.

16. Molad Y. Update on colchicine and its mechanism of action. Curr Rheumatol Rep. 2002;4(3):252-6.

17. Imazio M, Brucato A, Cemin R, Ferrua S, Belli R, Maestroni S, et al. CORP (COlchicine for Recurrent Pericarditis) Investigators. Colchicine for recurrent pericarditis (CORP): a randomized trial. Ann Intern Med. 2011;155:409414.

18. Imazio M, Demichelis B, Parrini I, Giuggia M, Cecchi E, Gaschino G, et al. Day-hospital treatment of acute pericarditis: a management program for outpatient therapy. J Am Coll Cardiol. 2004;43:1042-1046.

19. Brucato A, Brambilla G, Moreo A, et al. Long-term outcomes in difficulttotreat patients with recurrent pericarditis. Am J Cardiol 2006;98:267-71.

20. Imazio M, Brucato A, Cumetti D, Brambilla G, Demichelis B, Ferro S, et al. Corticosteroids for recurrent pericarditis: high versus low doses: a nonrandomized observation. Circulation. 2008;118:667-671.

21. Vianello F, Cinetto F, Cavraro M, Battisti A, Castelli M, Imbergamo S, et al. Azathioprine in isolated recurrent pericarditis: a single centre experience. nt J Cardiol. 2011;147(3):477-8.

22. Khandaker MH, Schaff HV, Greason KL,Anavekar NS, Espinosa RE, Hayes $\mathrm{SN}$, et al. Pericardiectomy vs medical management in patients with relapsing pericarditis. Mayo Clin Proc. 2012;87:1062-1070.

23. Lazaros G, Karavidas A, Spyropoulou M, et al. The role of the immunogenetic background in the development and recurrence of acute idiopathic pericarditis. Cardiology 2011;118:55-62. 